\title{
Um Sistema Curricular no Departamento de Artes Cênicas: Proposta Pedagógica Processual (ECA/USP)
}

\author{
José Batista (Zebba) Dal Farra Martins* \\ Departamento de Artes Cênicas \\ Escola de Comunicações e Artes da Universidade de São Paulo \\ * Autor para correspondência: dalfarra@usp.br
}

\section{RESUMO}

Este artigo visa a apresentar as principais componentes de um Sistema Curricular, nova proposta pedagógica do Departamento de Artes Cênicas (CAC-ECA-USP), baseada na articulação dinâmica de quatro Modos de Operação, quais sejam: disciplinas, ateliês, laboratórios e estágios. A proposição postula a imbricação constante entre os cursos de licenciatura e bacharelado, inter-relação que aponta para o artista-pesquisador-pedagogo como horizonte, e permitirá a dupla diplomação do aluno, ao cabo de doze semestres. Em síntese, no diálogo com poéticas contemporâneas, e suas dimensões estéticas, éticas e políticas, a proposta do Sistema Curricular visa a contribuir para a formação, no âmbito do bacharelado, de artistas teatrais que atuem como pesquisadores e pedagogos, e, no âmbito da licenciatura, pedagogos que atuem como pesquisadores e artistas.

Palavras-chave: Artista Teatral; Pesquisador; Pedagogo.

\begin{abstract}
This paper deals to present the main components of a Curricular System, a new pedagogical proposal of the Departamento de Artes Cênicas (CAC-ECA-USP), based on the dynamic articulation of four operating modes, namely: disciplines, ateliers, laboratories and stages. The proposition posits constant imbrication between the degree courses, interrelatedness that points to the artist-researcher-pedagogue as the horizon, and that will allow the double graduation of the student, in the period of twelve semesters. In the summary, in the dialogue with contemporary poetics, and its aesthetic, ethical and political dimensions, the proposal of the Curricular System aims to contribute to the formation of theater artists who operate as researchers and educators, and pedagogues who operate as researchers and artists
\end{abstract}

Keywords: Theatrical Artist; Researcher; Teacher.

1. No período de 2012 a 2014, o Departamento de Artes Cênicas empreendeu um extenso e importante debate acerca de seus objetivos e princípios metodológicos, tendo como horizonte o artista-pesquisador-pedagogo e como solo os fazeres e saberes teatrais. Dessa iniciativa, para a qual contribuíram de forma significativa docentes e discentes, originou-se a proposta de um Sistema Curricular ${ }^{1}$, a ser implantada em 2017, e fundamentada na integração - entendida como interdependência e interferência - dos processos criativos e pedagógicos. Postulamos, portanto, que a criação artística é essencial para o percurso de aprendizagem do professor, da mesma maneira que o é a ação pedagógica para o artista teatral. Os cursos de licenciatura e bacharelado se lastreiam no binômio teoria-prática e na construção da capacidade de transitar entre estes dois polos, em consonância com a cena teatral contemporânea, em que as especialidades não se definem com demasiada precisão. Tal perspectiva foi lançada em uma reformulação implantada em 2010, quando foram enunciados cinco princípios para o artista-pesquisador-pedagogo (DAL FARRA MARTINS, 2010), associados ao Bacharelado e à Licenciatura $^{2}$. Uma característica comum a esses princípios é a ênfase nos processos teatrais, entendendo-se os produtos como resultantes não definidos a priori. Torna-se requisito dos envolvidos a busca de uma atitude contínua e renovada de atenção e de escuta, para colocar o artista como sujeito da 
experiência teatral, entendendo-se que "a experiência é o que nos passa, o que nos acontece, o que nos toca. Não o que se passa, não o que acontece, ou o que toca. A cada dia se passam muitas coisas, porém, ao mesmo tempo, quase nada nos acontece. Dir-se-ia que tudo o que se passa está organizado para que nada nos aconteça" (LARROSA, 2002, pp. 20-28). O processo ensina.

$\mathrm{O}$ pesquisador aparece nas articulações do binômio teoria-prática (seja aquela pressuposta, seja esta tomada como objeto de análise), fundadas no pensar por si e pela intuição, por meio de leituras e proposições menos voltadas para o acúmulo de saberes gerais e mais direcionadas para os saberes gerados nos próprios processos artísticos de ensino. Não se trata de cultivar somente competências teóricas, mas de estimular a reflexão como pressuposto de todos os processos.

De forma semelhante, deseja-se que o pedagogo esteja presente em todos os processos, para se constituir a mirada para o outro e para o grupo a que pertence, em contraponto crítico com as relações estáticas e amiúde mediadas por aparelhos - celulares, computadores, telefones, televisores, intercomunicadores, interfones -, crescentemente comuns, na atualidade. $\mathrm{O}$ teatro se nutre dos suores dos afetos dos corpos e das vozes presentes. $\mathrm{O}$ pedagogo teatral lança laços orgânicos com a realidade social e política da cidade, como se enfiasse a mão na terra, sujasse de lama e fincasse rizomas com os grupos que trabalha. Já na perspectiva da reformulação de 2010 , os conteúdos pedagógicos irrigam os processos teatrais, tecidos a uma ação educativa e social. Do ponto de vista estrutural, houve a definição de um Ciclo Básico comum à Licenciatura e ao Bacharelado, com duração de quatro semestres, fator fundamental para o trânsito entre os dois cursos; e a criação da disciplina Processos Criativos e Pedagógicos, obrigatória para a Licenciatura e optativa eletiva para o Bacharelado. Uma análise do percurso nos anos de sua implantação mostrou que avançamos no intercâmbio entre esses dois campos, mas que um efetivo enfrentamento da questão da integração requer ações mais profundas, que propiciem a possibilidade de o aluno obter o duplo diploma e a abertura de outros espaços de troca.

2. No primeiro semestre de 2012, agrupamos conjuntos de disciplinas em torno de três projetos poéticos, definidos como espaços pedagógicos e criativos, conduzidos por três equipes de docentes, em solidariedade com os alunos. $\mathrm{O}$ adjetivo poético atribuía aos processos o aspecto da fabricação cênica e determinava os programas dos encontros, cujo alinhamento era fortemente instável em função dos fluxos dos projetos. Apesar dessa instabilidade, e em certa medida por causa dela, o envolvimento dos participantes e o consequente amadurecimento artístico foram notáveis, a ponto de justificar um fórum reflexivo, ocorrido em outubro daquele ano. Com ampla participação de alunos e professores, fundou-se aí a proposta do Sistema Curricular, desenvolvida e finalizada em 2013 e 2014. Diz-se sistema pois suas componentes em processo são fortemente interdependentes e suas inter-relações não lineares: iniciado o percurso, não se determina a priori o ponto de chegada.

Do ponto de vista metodológico, definimos quatro espaços integrados, chamados Modos de Operação: a disciplina, o ateliê, o laboratório e o estágio. As disciplinas subdividem-se em quatro categorias. $\mathrm{Na}$ primeira, impulsionam os ateliês; a segunda agrupa as matérias específicas dos cursos; a terceira se refere à problematização e à gestão dos estágios do Bacharelado e da Licenciatura; finalmente, a quarta categoria agrega as disciplinas optativas eletivas, articuladas às pesquisas dos docentes.

Frise-se que os quatro Modos de Operação não atuam isoladamente, mas de forma integrada e interferente, impulsionados por três vetores: processo, jogo e coletivo. Além disso, fixamos como orientação para o Domínio do Sistema o debate sobre o Moderno e o Contemporâneo nas Artes Cênicas, em confronto dinâmico e dialético com Estudos Brasileiros, deslocamento que introduz um leque de referências teóricas e práticas associadas às nossas especificidades históricas. A delimitação desses campos não exclui manifestações cênicas fora desse período: condiciona toda a abordagem dos cursos a ópticas 
de poéticas pedagógicas e criativas modernas e contemporâneas, em diálogo com outras tradições.

Todos os programas das componentes do Sistema Curricular se definem pela definição dos Campos Poéticos, recortes específicos e focalizados dentro do Domínio. Focos de trabalho anual comum, propostos no início de cada semestre ímpar, os Campos Poéticos direcionam concretamente os Modos de Operação, que agregam à tradicional estrutura disciplinar da universidade três outras modalidades metodológicas, para enriquecer a perspectiva de aprendizagem do artista-pesquisador-pedagogo: os ateliês, os laboratórios e os estágios. Os ateliês, oferecidos nos semestres pares, constituem o campo coletivo de ensaio prático e teórico, em que professores e alunos desenvolvem processos criativos e pedagógicos, preparados nos semestres ímpares anteriores, no modo disciplina. Os laboratórios, agentes catalisadores dos ateliês, trabalham de forma conjugada com eles, no desenvolvimento de conteúdos específicos necessários ao processo, e ocupam também os semestres pares. Finalmente, o Sistema Curricular proporcionará ao bacharelando a experiência em estágios de observação, realizados fora da universidade, junto a grupos teatrais. Esse Modo de Operação se associa aos estágios já obrigatórios para a Licenciatura.

3. No início dos anos 1960, apareceu uma família que saltava da película cotidiana de minha pequena cidade. Os cabelos longos e as botas do pai, com seu perfil agudo na mira da mirada, e a beleza ruiva e cáqui da mãe passeavam pela rua Amando de Barros ${ }^{3}$ sua presença estrangeira. Suas vozes arrastavam o brasileiro impresso no belga. O pai era uma figura impressionante, para quem cada suspensão do passo era um mergulho no vazio que a queda do pé preenchia. Herói da Segunda Guerra, morara no Congo Belga e na Amazônia, para depois subir a serra de Botucatu e se fixar, em definitivo, numa bela e estranha casa, incrustada em uma de suas ladeiras. Mestre de piano, aprendiz de um discípulo de Liszt. Seu método indutivo postulava que era no enfrentamento dos mínimos problemas que o aprendiz aprendia, ao contrário dos métodos dedutivos usuais, em que a técnica se desenvolve atrelada a um estoque de escalas de dificuldade crescente. A proposta pressupunha a experiência direta com peças pianísticas, independente do nível de dificuldade, no aprimoramento do pequeno fragmento, para passo a passo alcançar a totalidade da composição em estudo. Ao escolher outra partitura, problemas e processos se renovam, e assim sucessivamente. Neste enfoque plenamente poético, em que se aprende a tocar tocando, a escolha das peças de estudo será fundamental. Analogamente, para o Sistema Curricular, será essencial a definição do Campo Poético.

4. Os cursos se dividem em duas fases: o Ciclo Básico e o Ciclo Específico, cada um com duração (ideal) de quatro semestres. A divisão é necessária, na medida em que é preciso contemplar as especificidades do Bacharelado e da Licenciatura, enfatizadas após uma etapa inicial de processos criativos e pedagógicos.

No Ciclo Básico, os Modos de Operaşão, que determinam a matriz curricular, são comuns a bacharelandos e licenciandos. As disciplinas ocupam os semestres ímpares; os ateliês e os laboratórios, os pares. Há um encadeamento estratégico entre o primeiro e o segundo semestre, bem como entre o terceiro e o quarto, o que torna o planejamento anual. No Ciclo Específico, embora a opção do aluno determine atividades diferenciadas entre os cursos, há ainda modos comuns e uma consistente solidariedade entre eles. No quarto e último ano, todas as atividades são integradas em torno de trabalhos coletivos, fundados em estudos práticos e teóricos, criativos e pedagógicos.

5. Conforme expresso anteriormente, definimos três vetores, entendidos como operadores de todas as ações do Sistema Curricular: processo, jogo e coletivo. Os vetores potencializam o enfrentamento do principal desafio da proposta, qual seja, a de criar relações solidárias e recíprocas entre processos criativos e pedagógicos. O vetor processo reafirma a preponderância e valorização dos percursos criativos e pedagógicos sobre os resultados finais. Os cursos se baseiam na experiência, observação e análise desses processos, sem privilegiar a realização de produtos cênicos acabados, ainda que estes componham a tarefa dos artistas teatrais. 
Estimulam-se, assim, a experimentação e o risco, ao invés da repetição ou reprodução de modelos cênicos conhecidos ou conformados pelo mercado.

O vetor jogo aparece como um estímulo a uma atitude relacional na abordagem do estudo das Artes Cênicas. Ele se contrapõe a uma tendência de instrumentalização das habilidades e especialização dos fazeres cênicos. Seu motor fundamental é o prazer do aprendizado e da interação com o outro, com base em acordos coletivos. Nessa perspectiva, escuta, contato, relação e presença são componentes do vetor jogo.

$\mathrm{O}$ vetor coletivo, articulado plenamente aos dois primeiros vetores, enfatiza o caráter grupal das artes cênicas e problematiza a prática cênica em conexão com o individual.

6. Eis um exemplo do Sistema, tomado do primeiro ano do Ciclo Básico. Com os programas formulados e especificados a partir da predefinição do Campo Poético, tem-se, no primeiro semestre, o seguinte conjunto de disciplinas: Poéticas de Atuação I, Dramaturgia I, Poéticas de Encenação I, Processos Criativos e Pedagógicos I e Estética, Teoria e Crítica das Artes Cênicas I. Todas essas disciplinas desenvolverão conteúdos históricos, teóricos e práticos, delimitados pelo Campo Poético. Assim, às Poéticas de Atuação I corresponderão tópicos sobre a História, a Teoria e a Prática da Atuação. O programa da disciplina Dramaturgia I vai conter elementos de História, Teoria e Prática da Dramaturgia - entendida como tessitura de ações textuais e cênicas -, sempre recortados pelo Campo Poético. Além de se constituir em atividade pedagógica em si, esse semestre tem a função de preparar o seguinte, mantendo-se, portanto, o mesmo Campo Poético.

No segundo semestre, alteram-se os Modos de Operação para ateliê e laboratórios: Ateliê I, Laboratório IA, Laboratório IB, Laboratório IC. O Ateliê I, conduzido por quatro professores que ministraram disciplinas no primeiro semestre, prevê doze horas-aula e doze horas-trabalho semanais, estas para a realização de ensaios e tarefas, orientadas por monitores. Três laboratórios, de quatro horas semanais, ampliam certos conteúdos técnicos necessários para os processos desenvolvidos no ateliê.
O aluno deve participar de dois dos três laboratórios, segundo sua área de interesse.

7. Em síntese, no diálogo com poéticas contemporâneas e suas dimensões estéticas, éticas e políticas, a proposta do Sistema Curricular visa a contribuir para a formação, no âmbito do Bacharelado, de artistas teatrais que desenvolvam competências como pesquisadores e pedagogos, e, no âmbito da Licenciatura, de pedagogos que desenvolvam competências como pesquisadores e artistas.

O Bacharelado em Artes Cênicas, em relação solidária com a Licenciatura, busca fomentar o conhecimento e o exercício teórico e prático de ancoradouros poéticos e técnicos, baseados na experimentação e no risco, na observação e na análise dos fundamentos que regem o processo de criação cênica, sem privilegiar a realização de produtos acabados. Propõe-se ao aluno o reconhecimento das lacunas e das possibilidades poéticas e pedagógicas reveladas pelas escolhas artísticas e pela organização cênica que realiza a cada tarefa teatral. Desse modo, pode-se transitar entre os modelos da tradição e os novos paradigmas da cena contemporânea. O curso se organiza a partir de diferentes matrizes da história do teatro e de outras áreas do conhecimento, denominadas Campos Poéticos, permitindo-se ao aluno a produção de processos perceptivos, a elaboração e a concretização de um discurso artístico singular. O aluno é um agente que constrói ativamente o seu conhecimento e competências teóricas e práticas necessárias à criação. No percurso criativo, a documentação e o registro, associados à leitura e à análise do lido, são instrumentos fundamentais para a formação do pesquisador. $\mathrm{O}$ incentivo à produção de artigos temáticos e de relatos de processo para publicações internas, e o estreitamento dos vínculos com a pós-graduação são algumas estratégias para desenvolver uma cultura de pesquisa. A experiência proposta pelo Bacharelado em Artes Cênicas pressupõe a interdisciplinaridade e a integração, tanto no que diz respeito às diferentes práticas artísticas, quanto aos diferentes campos do conhecimento: teatro 
e ciência; teatro e filosofia; teatro e tecnologia etc. $\mathrm{O}$ aluno deve compreender que seu processo formativo não se conclui ao término da graduação, como também deve dialogar com o processo de formação de seus parceiros e colaboradores - atores, diretores, cenógrafos, iluminadores etc. $\mathrm{Tal}$ processo inclui uma perspectiva ética, tanto no que se refere às relações intragrupais, quanto na proposição de uma ação cultural no âmbito da sociedade. O Bacharelado em Artes Cênicas pretende ser um espaço de problematização de saberes e fazeres teatrais, de interrogação e busca contínuas, bem como uma possibilidade de articulação e apontamento de novos saberes e fazeres da cena contemporânea. Trata-se de criar um espaço de pesquisa e investigação da linguagem, que possibilite ao aluno formular, transformar e refletir sua prática, como também ser portador e transmissor desse conhecimento na sociedade.

O modo contemporâneo de pensar o teatro e as conquistas atuais das ciências da educação, além da contribuição de diferentes áreas das ciências humanas, formam o arcabouço teórico a partir do qual se procura constituir elementos para a Licenciatura em Artes Cênicas. Espera-se que o licenciado se sinta estimulado e apto a pensar a relação entre teatro, educação e sociedade em nossos dias, relação esta que, por caracterizar-se como construção realizada historicamente, solicita respostas sempre apropriadas ao momento histórico e necessita ser constantemente revisada. Pretende-se a formação de um artista cênico e educador presente no presente, em condição de propor soluções próprias para os variados desafios que certamente encontrará em seu campo de trabalho, disposto a criar e propor outros caminhos de atuação - sempre por serem inventados - em que o teatro e a pedagogia se encontrem em diálogo franco e produtivo. A intenção é que os estudantes sejam capazes de instaurar uma prática artística plena, tecida a uma ação educativa, social, visando à ampliação da consciência de quem a vive. A Licenciatura em Artes Cênicas, em relação solidária com o Bacharelado, volta-se à formação de um profissional capaz de se valer de suas intervenções de modo a transformá-las em contínuas investigações sobre processos de aprendizagem em teatro. O profissional que se tem em vista deve ser capaz de propor processos artísticos em sintonia com as demandas das pessoas, do contexto e do momento em que seja solicitado a atuar. Deve coordenar atividades nos mais diferentes campos em que a arte teatral seja proposta como modalidade privilegiada, a saber: educação formal - em escolas de Educação Infantil, Ensino Fundamental e Ensino Médio; ação sociocultural - na esfera de políticas públicas, ONGs, centros culturais, associações, prisões e em outros contextos.

Em ambas as frentes apontadas, a atuação do licenciado visa tanto ao fazer teatral quanto à recepção dessa arte, enfocando a dimensão pedagógica da relação do espectador com a obra teatral e as diferentes instâncias que podem contribuir para a formação de espectadores.

8. Os alunos da licenciatura e do bacharelado poderão optar pela dupla titulação, realizada simultaneamente ou consecutivamente, no período máximo de doze semestres. Essa importante conquista exige a unificação dos vestibulares de licenciatura e bacharelado, bem como das vagas, ampliadas de 25 para trinta. Ao ingressar no Ciclo Básico, o aluno detém duas vagas, que só serão destinadas à Licenciatura e/ou ao Bacharelado, por uma opção, no fim do quarto semestre. Além disso, dissolveram-se as habilitações do Bacharelado, focando-se plenamente o artista-pesquisador-pedagogo.

\section{Notas}

1 Este artigo se baseia nas discussões e no Projeto Político Pedagógico gerado a partir delas, formulado pelos docentes, com a participação discente, no período de 2012 a 2014.

2 O Bacharelado do Departamento de Artes Cênicas oferece atualmente quinze vagas anuais para as habilitações em Cenografia, Direção Teatral, Interpretação Teatral e Teoria do Teatro. Para a Licenciatura, entram dez alunos por ano. O vestibular se faz em separado. O Sistema Curricular exige o vestibular unificado e amplia o número de vagas para trinta.

3 Principal rua de comércio de Botucatu. 


\section{Referências Bibliográficas}

ARAÚJO, Antonio; AZEVEDO, Elisabeth; BASTOS, Helena; BULHÕES, Marcos; CARVALHO, Sérgio; CINTRA, Fábio; COSTA, Felisberto; COUTINHO, Eduardo; DAL FARRA, Zebba; DENNY, Marcelo; DESGRANGES, Flávio; FERNANDES, Sílvia; FORJAZ, Cibele; GAMA, Joaquim; KYIOMI, Alice; LOPES, Elisabeth; NUHR, Andréia; PUPO, Maria Lúcia; RAMOS,
Luiz; SANTOS, Maria Thaís; PEREIRA, Sayonara; VIANA, Fausto. Projeto Político Pedagógico: Sistema Curricular. Departamento de Artes Cênicas, 2014.

DAL FARRA MARTINS, José Batista (Zebba). "O Artista-Pesquisador-Pedagogo". VI Congresso da Abrace, São Paulo, 2010.

LARROSA, Jorge. "Notas sobre a Experiência e o Saber de Experiência". Revista Brasileira de Educaşão, Rio de Janeiro, n. 19, 2002, pp. 20-28.

Publicado em 11/11/2016. 